\title{
e-Doculnfo/TVDoc: portal de documentación informativa-canal temático iptv
}

\author{
Por Alfonso López-Yepes y Rodrigo Sánchez-Jiménez
}

\begin{abstract}
Resumen: La creación de un portal de documentación informativa (e-DocuInfo) que integra y posibilita el acceso a un canal temático de televisión vía internet (iptv) sobre documentación, tiene como objetivo la difusión de contenidos y la generación de una programación en el ámbito documental, de forma distribuida y colaborativa, en estrecha relación con los parámetros de la web 2.0 o web social. El portal, entendido como plataforma universitaria en línea en tiempo real, supone la creación y puesta a disposición de docentes, discentes, investigadores y profesionales de medios de comunicación de una amplia variedad de materiales multimedia, didácticos y de aplicación al ámbito profesional. El canal de televisión, que puede emitir información en tiempo real o en diferido (vídeo bajo demanda) vehicula información de la mediateca del portal a través de un servidor de streaming. La existencia del portal se beneficia asimismo, por sus mayores posibilidades de difusión informativa, de la coordinación asumida por el servicio de documentación multimedia (en cuyo ámbito nace e-DocuInfo/TVDoc) para el acceso de la facultad de ciencias de la información al campus virtual de la universidad complutense.
\end{abstract}

Palabras clave: Campus virtual, Documentación en medios de comunicación social, Portal de documentación informativa, Enseñanza multimedia, Investigación multimedia, Producción multimedia, Mediateca, Espacio de Coordinación de Centro, Televisión por internet, Iptv, Video bajo demanda

Title: e-Doculnfo/TVDoc: a thematic channel iptv portal for mass media information management

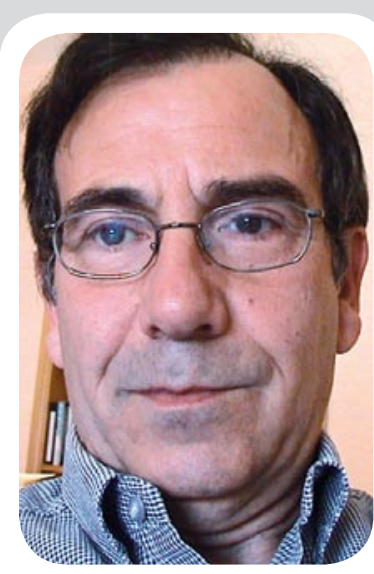

Alfonso López Yepes es catedrático de documentación, director del Servicio de Documentación Multimedia de la Universidad Complutense y director de la revista Cuadernos de documentación multimedia. Dirige el doctorado iberoamericano presencial y en línea "Documentación: fundamentos, tecnología y aplicaciones (2007-2009)". Responsable en la facultad de ciencias de la información de Madrid del Espacio de Coordinación de Centro para el acceso al campus virtual de la UCM.

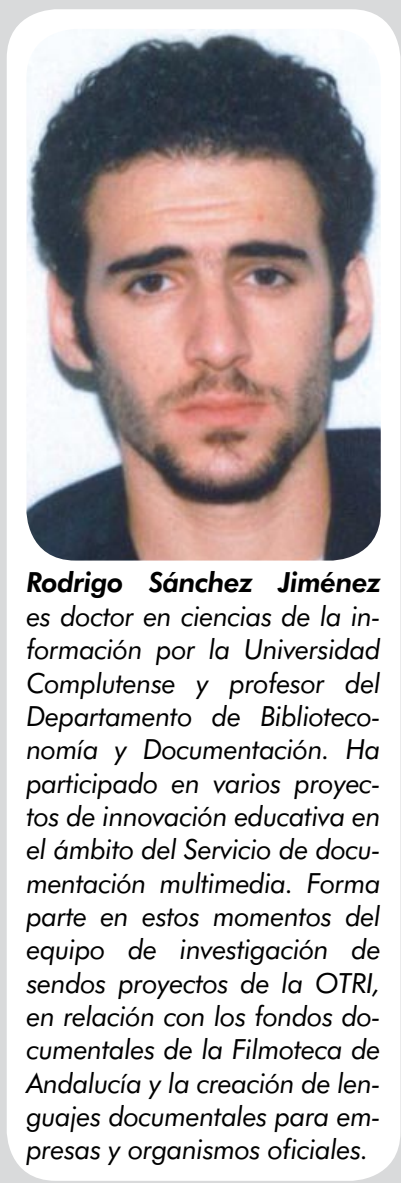

Abstract: A mass media information management web portal that effectively integrates access to documentation of a thematic channel via iptv was created to disseminate content and generate programmes related to documentation. This is accomplished in a distributed and collaborative fashion, using the web 2.0 or social web parameters. The web portal is an online university platform that supports the creation and diffusion of a wide variety of multimedia and didactic materials as a resource to lecturers, students and professionals. The TV channel is able to transmit live or on demand, carrying content from the newspaper library, image library, video library, or the complete media library using streaming and other technologies. This web portal also benefits from the fact that the multimedia documentation service coordinates access to e-learning tools in the Information Sciences Faculty. E-DocuInfo/TVDoc emerged precisely at the centre of this environment.

Keywords: Virtual campus, Mass media information management, Portals, Education and multimedia, Multimedia research, Multimedia production, Media libraries, e-learning, Television on the internet, Iptv, Video on demand.

López-Yepes, Alfonso; Sánchez-Jiménez, Rodrigo. “e-DocuInfo/TVDoc: portal de documentación informativa-canal temático iptv”. En: El profesional de la información, 2007, septiembre-octubre, v. 16, n. 5, pp. 456-467.

DOI: $10.3145 /$ epi.2007.sep.08

Info@Sociedad: Programa I+D de Interés Regional de la Comunidad Autónoma de Madrid

INFO@SOCIEDAD ES UN PROYECTO FINANCIADO (aun- que pendiente de adjudicación definitiva en el momento de elaboración de estas páginas) por la Comunidad de Madrid (CAM). Se trata de un colectivo multidisciplinar compuesto por seis grupos de investigación sobre derecho constitucional (grupo 1), empresa (2), documentación (3 y 4) y comunicación audiovisual ( 5 y 6$)$.

$\mathrm{Su}$ objetivo es analizar los desafíos de la revolución tecnológica 
tanto para los medios, los ciudadanos y las administraciones públicas, como para las empresas proveedoras de contenidos audiovisuales, las universidades y sus investigadores, con un claro enfoque hacia el ciudadano, la cultura y la sociedad a través de tres tecnologías de la información y la comunicación (TIC): internet, televisión digital y documentación electrónica. Uno de los objetivos estratégicos de este proyecto colaborativo es la creación de ciencia y la difusión de sus resultados como consecuencia de la participación y la distribución del conocimiento.

El conjunto del proyecto se identifica con tres de los objetivos estratégicos de la CAM en esta convocatoria:

- Generar trabajo colaborativo de grupos de I+D.

- Dar mayor visibilidad a los resultados de la comunidad académica, con especial importancia a la referencia internacional.

- Crear y editar contenidos para la documentación y difusión de la cultura en coordinación con los actuales servicios y portales de Madrid $+d$.

Los dos grupos (3 y 4) de investigación en documentación, surgidos en el seno del Departamento de Biblioteconomía y Documentación de la Universidad Complutense, son Publidoc y e-DocuInfo. Mientras que el primero está más orientado a las políticas y publicaciones de las administraciones públicas, el segundo trata del diseño y generación de materiales multimedia sobre documentación informativa y medios de comunicación social mediante la integración, entre otros contenidos, de portales aplicados a la docencia, investigación y producción multimedia en materia de ciencias de la información (figura 1).

PubliDoc supone, en continuidad con el plan de I+D nacional en el que ya está involucrado (por

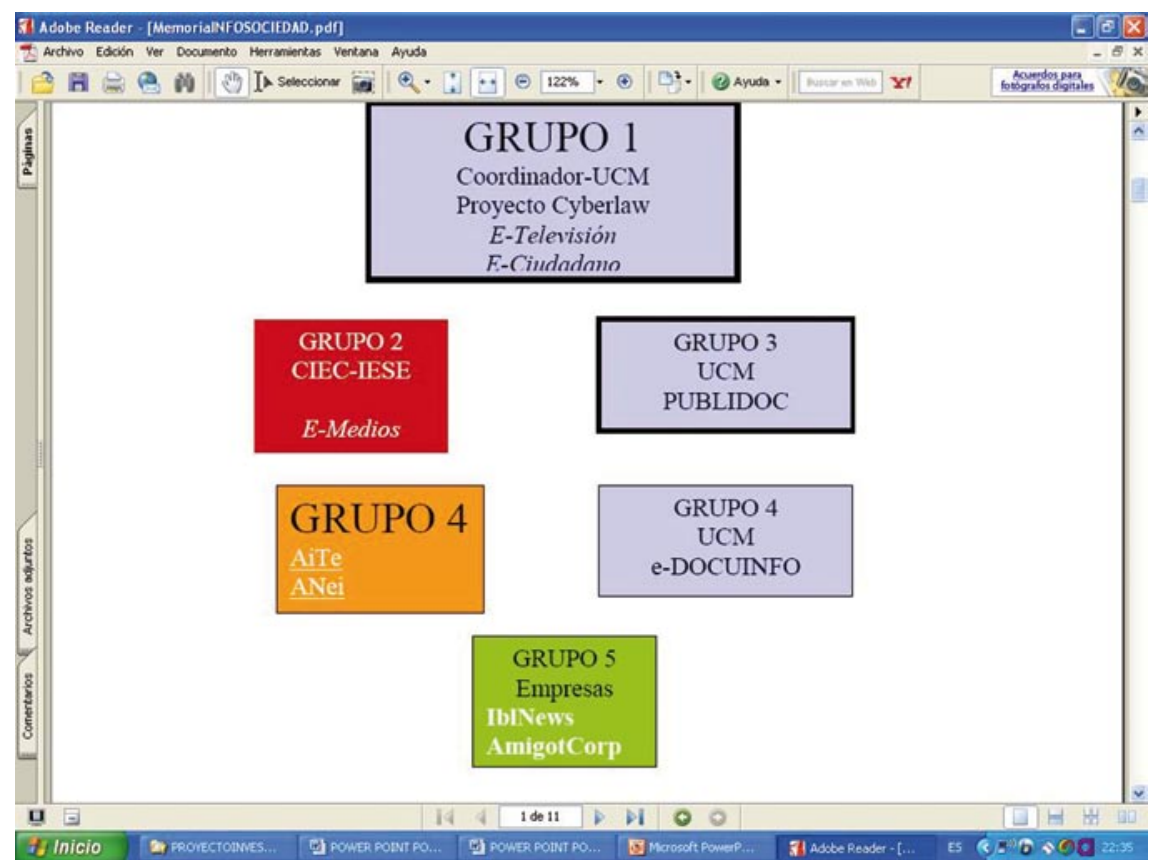

Figura 1.Info@Sociedad: grupos de investigación

consiguiente vigente en este momento), el estudio exhaustivo de las publicaciones oficiales electrónicas de la administración. Más concretamente se propone identificar, describir, analizar y evaluar los repositorios digitales de información y documentación pública, de acuerdo con las siguientes acciones investigadoras en proceso de desarrollo:

- Localización e identificación de los repositorios digitales de información y documentación pública.

- Determinación de los campos de análisis y descripción de sus características.

- Obtención de datos para el análisis formal.

- Recogida y análisis de resultados.

- Valoración de los datos e interpretación de los resultados.

- Obtención de conclusiones.

- Difusión y publicación de resultados en, al menos, un artículo publicado en una revista de impacto del área de biblioteconomía y documentación.

- Creación y mantenimiento actualizado de un observatorio de información y documentación pública como plataforma web que aglutine todos los resultados de la investigación realizada por este grupo de investigación.

\section{e-Doculnfo: portal de documentación informativa}

$\mathrm{Su}$ establecimiento (figura 2) es consecuencia del incremento de contenidos en los últimos seis años del Servicio de Documentación Multimedia (Multidoc) de la Facultad de Ciencias de la Información de la $U C M$, como resultado de actuaciones académico-formativas:

- publicaciones electrónicas,

- proyectos de investigación en recuperación de información y en web semántica,

- formación semipresencial y virtual,

- programación,

- digitalización de fondos documentales de instituciones cinematográficas, etc.;

En suma, diversas líneas de I+D en muy estrecha relación con la documentación informativa ${ }^{1}$.

http://multidoc.rediris.es/edocuinfo 


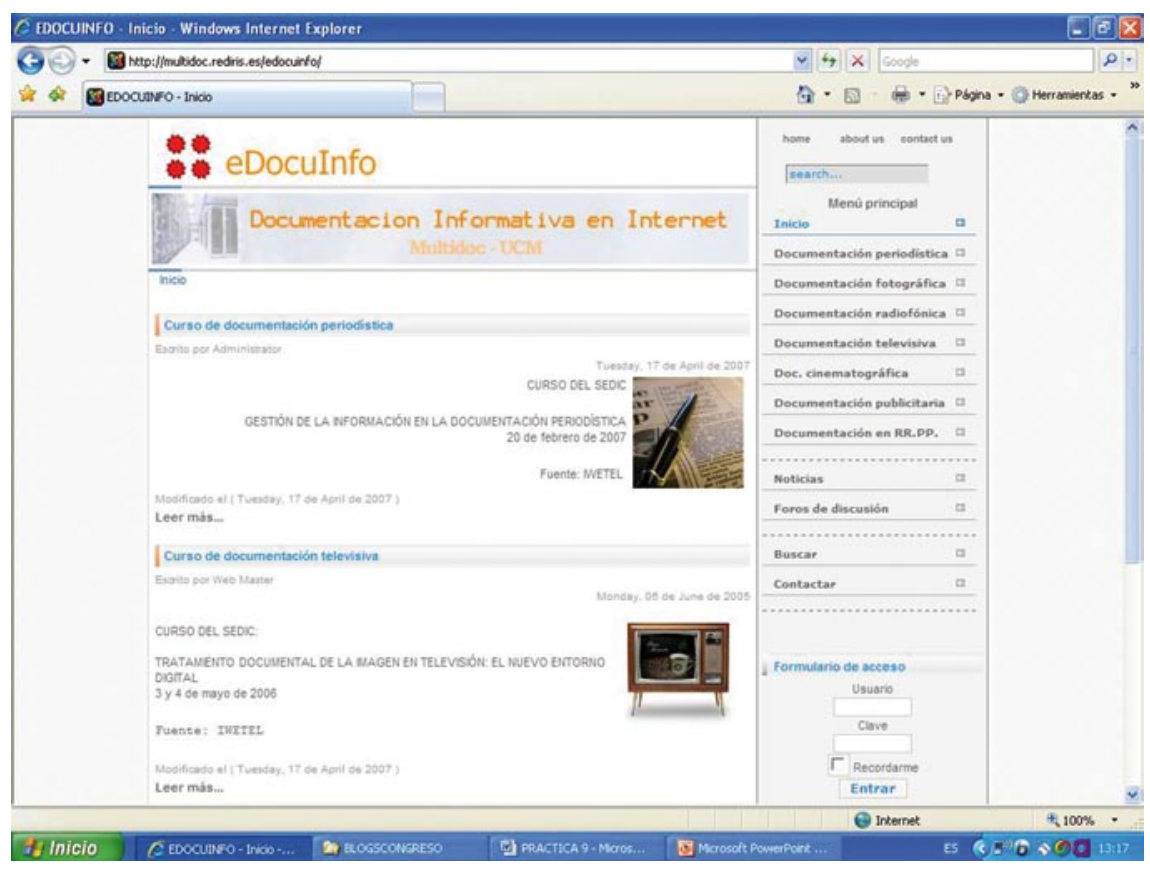

Figura 2. e-Doculnfo: página de bienvenida

\section{http://multidoc.rediris.es}

e-DocuInfo afronta las siguientes líneas de estudio, investigación y desarrollo:

- Creación y fomento de una comunidad virtual de usuarios de documentación informativa.

- Conocimiento distribuido y colaborativo como filosofía que subyace en la estructura de contenidos que presenta el portal.

- Proyectos de investigación y difusión de la producción propia de la Facultad de Ciencias de la Información y de sus profesores, alumnos, investigadores y profesionales de los medios de comunicación social (sobre temáticas del portal), independientemente de la extensión a otras universidades nacionales e internacionales e instituciones especializadas.

- Mentalización en el uso de internet y del campus virtual de la Universidad Complutense $\mathrm{y}$, por extensión, de los de otras universidades y ámbitos de estudio e investigación relacionados con documentación informativa, al mismo tiempo que proporciona fondos documentales relevantes en la conformación de asignaturas, tanto pre- nidad virtual de usuarios de documentación informativa, en la que el usuario real y potencial participa en todo momento con aportaciones y sugerencias, filosofía que caracteriza a la ahora denominada web 2.0 o red social. Y en relación con las actividades desplegadas vía web, el proyecto se beneficia del hecho de que el departamento de biblioteconomía y documentación coordina para toda la facultad (que acoge a unos 7.300 estudiantes y más de 300 profesores) el acceso al campus a través del Espacio de Coordinación de Centro (ECC). A fecha 6 de junio de 2007 se podía acceder a unas 300.000 páginas, encontrándose virtualizadas 4.912 asignaturas $(46 \%$ de las que se imparten en la $U C M$ ) e inscritos en el campus 61.445 estudiantes y 3.450 profesores $^{2}$. Conviene añadir que también se puede acceder al campus a través de la red inalámbrica local (wi-fi), previo registro.

https://www.ucm.es/info/ uatd/CVUCM/index.php?ac= mostrarCoor estos momentos, con el objetivd llegar a un definitivo doctorado de documentación en línea con Iberoamérica (ya se imparte de modo presencial y en línea un doctorado iberoamericano de documentación, 2007-2009), a lo que contribuye desde 2005 el título propio en línea "Gestor de información digital en medios de comunicación social".

- Contribución a la preservación y difusión del patrimonio de la empresa informativa, mediante el establecimiento de fondos en red e interconexión de instituciones informativas.

El portal, como producto final de la investigación, se presenta como una futura y verdadera comu-

http://www.ucm.es/campusvirtual

\section{http://ssii.ucm.es/wifil}

Los objetivos científico-tecnológicos de $e$-DocuInfo se resumen fundamentalmente en dos: producción de contenidos multimedia dirigidos al ámbito docente e investigador, y su correspondiente recuperación y difusión informativas; e información científica basada en la investigación, el debate y la intercomunicación en documentación informativa. De esta forma los contenidos alojados en el portal se estructuran en secciones sobre do-

\section{"e-Doculnfo puede entenderse como una comunidad virtual de usuarios aplicada a la docencia, investigación y producción multimedia en el ámbito de la documentación informativa"}


cumentación periodística, sonora, audiovisual, publicitaria y de relaciones públicas y multimedia, sistematizadas en los siguientes bloques temáticos: investigación, servicios y centros de documentación en medios de comunicación social, tecnología digital, formación, publicaciones y bases de datos, propiedad intelectual y derechos de autor.

Esos ámbitos temáticos se vertebran asimismo en diversas parcelas de estudio e investigación en las que el portal se especializa: título propio, investigaciones de alumnos, proyectos de investigación, formación semipresencial, formación virtual, libros electrónicos, sub-portales (cine, publicidad, relaciones públicas y publicaciones electrónicas de documentación generados en fases anteriores como resultado de proyectos de investigación; en este sentido e-DocuInfo podría entenderse como un portal de portales), doctorado en línea, materiales didácticos multimedia producto de proyectos de innovación educativa $\operatorname{previos}^{3}$ (figuras 3, 4, 5, 6, 7).

Se tiene previsto a medio plazo el establecimiento y puesta en funcionamiento de otros sub-portales, relacionados estrechamente con televisión, prensa y radio en el ámbito obviamente de la documentación. Conviene destacar que todas las secciones y su desarrollo temático están coordinados por profesores del Departamento de Biblioteconomía y Documentación, quienes se ocupan precisamente de impartir en la Facultad de Ciencias de la Información la asignatura troncal "Documentación informativa", dirigida a más de 3.000 alumnos en dicho centro.

Por otra parte, el segundo objetivo (véase para más información el siguiente epígrafe), propiamente tecnológico, se sustenta en los recursos que proporciona internet $\mathrm{y}$ las herramientas de hardware $\mathrm{y}$ software de que dispone el equipo de investigación en el que se sostie-

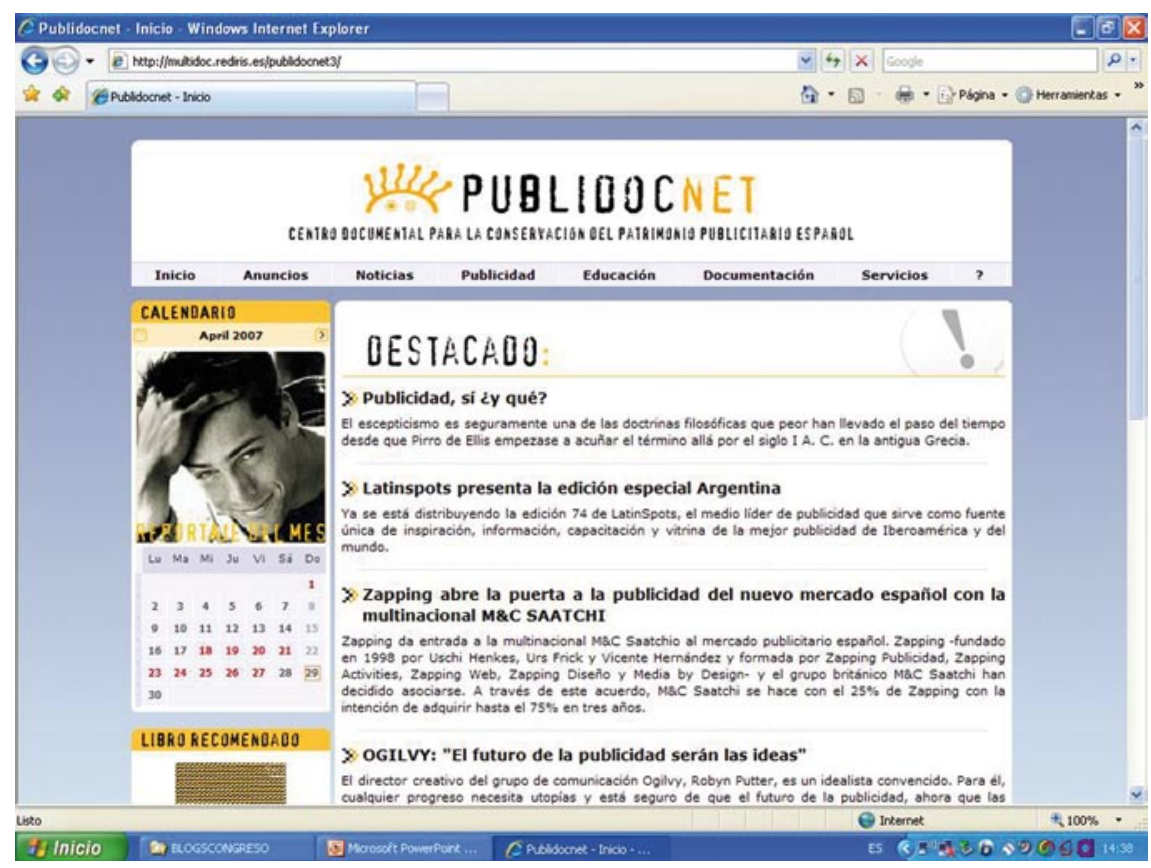

Figura 3. e-Doculnfo: portal de documentación publicitaria http://multidoc.rediris.es/publidocnet3/

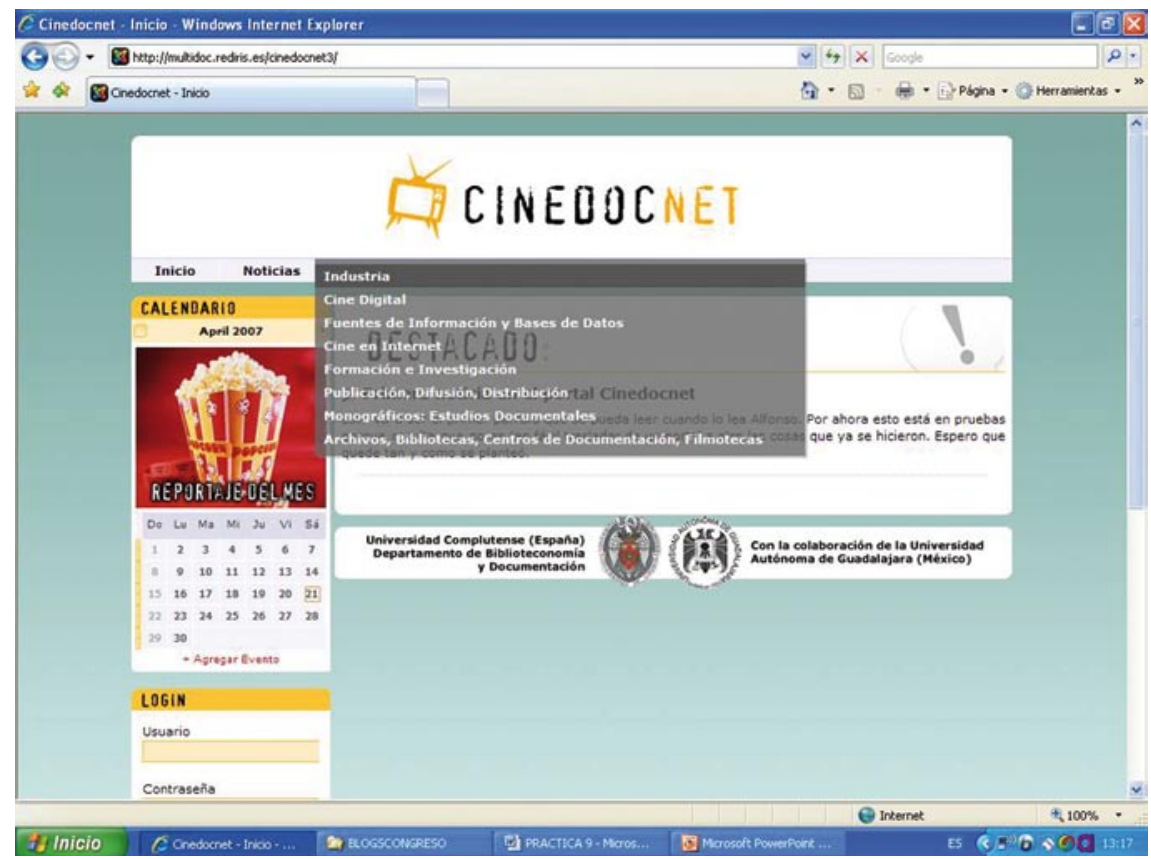

Figura 4. e-Doculnfo: portal de documentación cinematográfica http://multidoc.rediris.es/seguridad/descarga/cinedocnet/ http://multidoc.rediris.es/cinedocnet3/

ne el proyecto. Se propone, en consecuencia, el uso intensivo de las posibilidades del portal como vehículo de producción, recuperación y difusión de contenidos a través de una "ventana", canal temático de documentación informativa que vehicula por una parte una mediateca en línea (fonoteca, fototeca, videoteca, hemeroteca, etc.) a modo de archivo multimedia bajo demanda.
Por otra, programación en tiempo real (defensa de tesis doctorales, seminarios, entrevistas, etc.) y en diferido (a la carta). Todo ello incluso con calidad broadcast, en función del servidor de streaming al que tiene acceso la plataforma propuesta.

Finalmente, en la línea de trabajo experimental que caracteriza al Servicio de Documentación Multimedia de trabajar con software de 


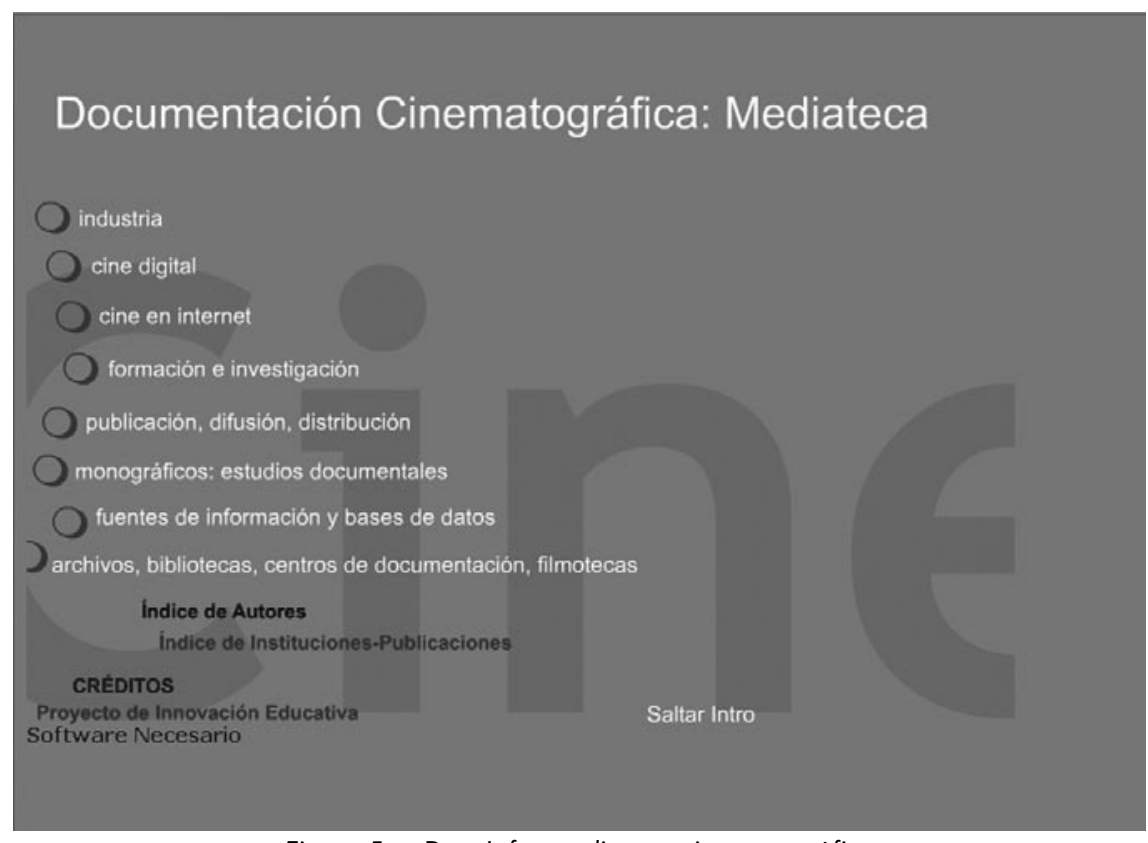

Figura 5. e-Doculnfo: mediateca cinematográfica http://multidoc.rediris.es/mediateca/

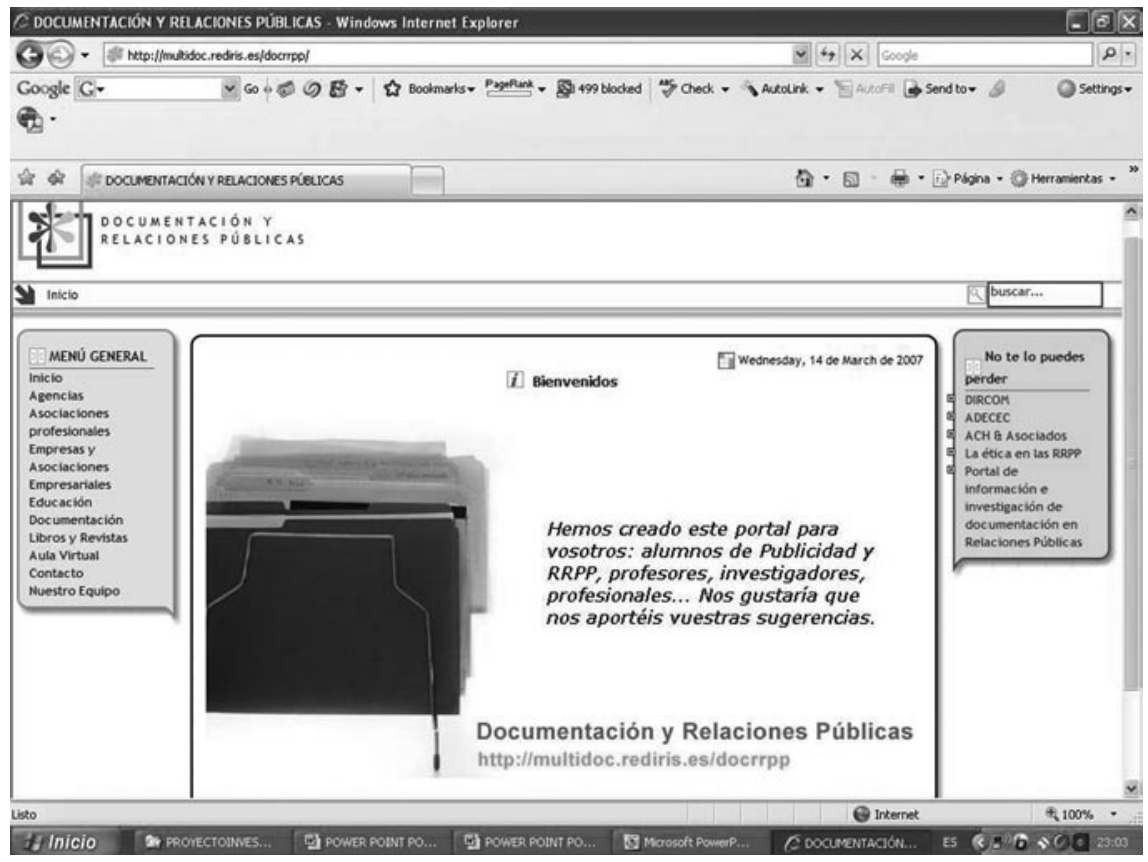

Figura 6. e-Doculnfo: portal de documentación en relaciones públicas http://multidoc.rediris.es/docrrpp/

código abierto, el portal ha sido diseñado con Joomla, versión 1.0.11. Asimismo, dispone de una serie de instrumentos y herramientas para la generación de contenidos y comunicación, como foros, blogs, chat, entre otras posibilidades de trabajo, así como un motor de recuperación, sindicación de contenidos y un formulario de acceso para los usuarios.

http://joomla.org

\section{Iptv y TVDoc: canal temático de documentación por televisión vía internet}

Puede afirmarse que 2007, con el aumento general del ancho de banda, ha augurado el inicio de la era del acceso a contenidos bajo demanda con calidad suficiente para rivalizar con los servicios tradicionales de televisión. La evolución y
"TVDoc es accesible a través del portal eDoculnfo, y emite información sistematizada en tiempo real (streaming) y en diferido"

la tecnología afecta incluso a plataformas de banda ancha móviles. Estadísticas recientes avanzan que el número de hogares con acceso a servicios iptv (sistema de distribución de televisión y vídeo sobre Ip) llegará de los 6 millones actuales a los 80 en 2011 (a nivel mundial). Los medios de comunicación digitales ya son los más utilizados entre la población mundial, que le dedican más horas semanales que a la televisión, la radio, los periódicos o el cine, según la Unión Internacional de Telecomunicaciones (UIT). Además de digitales y móviles, la UIT enfatiza que las comunicaciones también son cada vez "más anchas", porque las redes aumentan su capacidad de manera exponencial, lo que permite intercambios de información más rápidos, más completos y en más formatos simultáneos.

De hecho, según el informe anual sobre sociedad de la información presentado por Telefónica el pasado 1 de febrero de 2007, en el mundo ya hay 216 millones de suscriptores a líneas fijas de banda ancha y más de 61 millones de suscriptores a líneas móviles del mismo tipo (a través de la telefonía de tercera generación). En el ranking mundial de conexiones fijas por banda ancha EUA tiene 49 millones; China, 37; Japón, 22; Corea del Sur y Alemania, 12; Reino Unido y Francia, 9; Italia, 7; Canadá, 6; España, 5; Taiwán y Holanda, 4; Brasil, 3; México, Australia, Bélgica, Suecia y Suiza, 2, y Hong Kong y Turquía, 1. Asimismo, el precio de la banda ancha y de las conexio- 


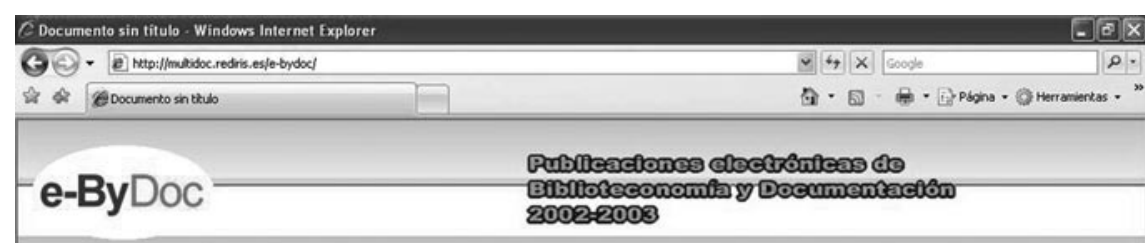

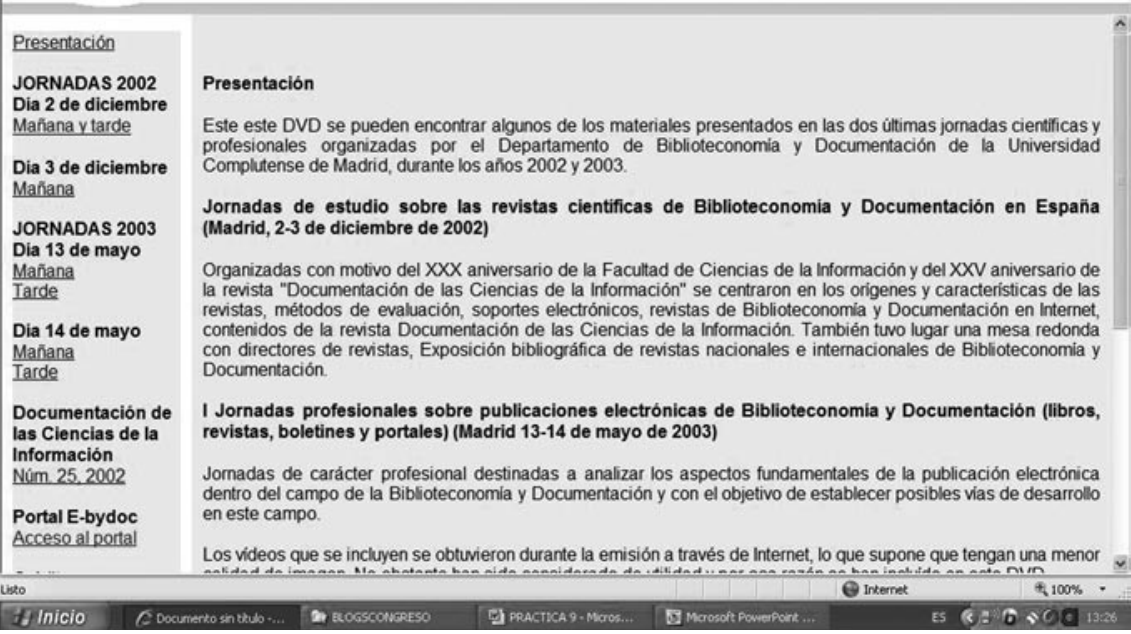

Figura 7. e-Doculnfo: portal de publicaciones electrónicas de ByD http://multidoc.rediris.es/e-bydoc/

nes inalámbricas se reduce a pasos agigantados en muchos países, por lo que las tecnologías de la información y de la comunicación cada vez ocupan más ámbitos de la vida privada. La combinación de TV e internet busca dar un paso pionero de convergencia entre dos medios para sumar la masividad del medio televisivo con la interactividad de la web, y el impacto estético de la pantalla de la televisión con la información personalizada en el PC de los usuarios; la fuerza narrativa televisiva con las múltiples posibilidades del relato web. Se busca transformar a los televidentes en usuarios, en participantes de la programación $\mathrm{y}$ en productores/transformadores de contenidos mediáticos, mediante la puesta a su disposición de contenidos ${ }^{4}$

El incremento actual del nivel de conectividad a través de sistemas de banda ancha (ADSL, cable, módem, $P L C$, etc.) para cientos de millones de usuarios de internet a nivel global, ha propiciado un tráfico masivo de obras culturales en la Red. El caso de EUA con una comunidad hispana de 40 millones altamente conectada, e Iberoamérica que se perfila como uno de los mundo, siendo las que mayor crecimiento experimentarán las de Europa y Asia-Pacífico ${ }^{5}$.

Como se ha dicho, España es el décimo país del mundo por número de conexiones de banda ancha. De los entre cinco a siete millones de conexiones de este tipo existentes en nuestro país, cerca de dos millones corresponden a hogares, donde una de las principales motivaciones a la hora de contratar este servicio es el acceso gratuito a archivos de música y cine. España lidera el ranking europeo de descargas ilegales de películas: entre junio de 2005 y junio de 2006 los españoles descargaron 132 millones de archivos de películas a través de las redes $P 2 P^{6}$.

La convergencia tecnológica (p. ej., últimamente puede verse televisión por el teléfono móvil) también está representada, entre otras, por la empresa española Overon y su servicio de transmisión por Ip para canales de TV y radio, que asimismo ofrece un valor añadido en forma de visualizador personalizado. Se ocupa de codificar y gestionar los más de 60 canales de Orange de TV por $A D S L$; también difundió un concierto del grupo Amaral que se

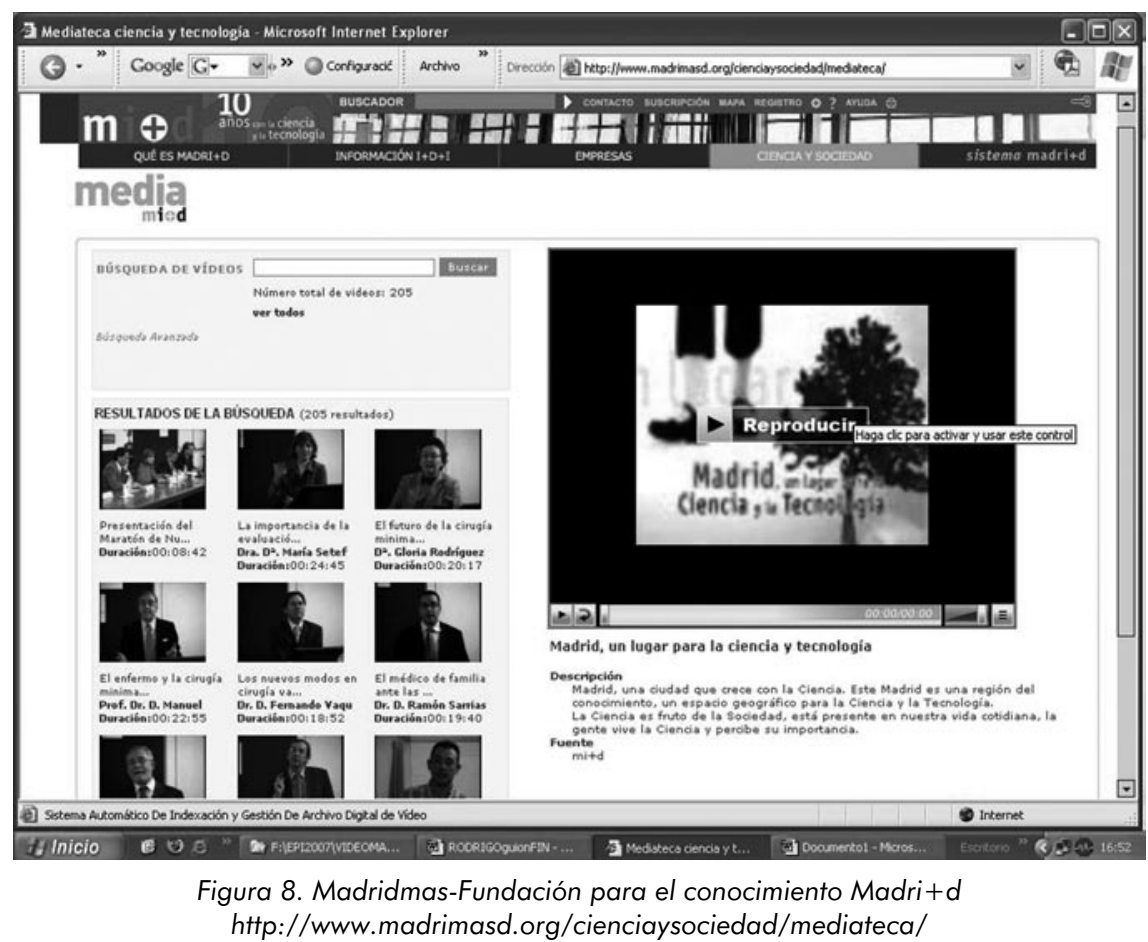


recibió en streaming Ip vía teléfono móvil e internet. Su red soporta 40.000 usuarios simultáneos para televisión y 750.000 para radio ${ }^{7}$.

En este contexto, una serie de instituciones y empresas públicas y privadas han implementado servicios iptv como, por ejemplo, YouTube, Googlevideo, MadridmasFundación para el conocimiento Madritd e Internautas TV, o la Universidad Politécnica de Valen$\mathrm{Cia}^{8}$ (figuras 8, 9). También el Departamento de Biblioteconomía y Documentación de la Universidad Complutense, a través de su Servicio de Documentación MultimediaMultidoc y del Taller Multimedia Complutense e integrada (como ya se ha explicado) en $e$-DocuInfo, ha propuesto la puesta en marcha de una plataforma de televisión en línea o canal temático de documentación (TVDoc) para emisión de programación en tiempo real (streaming) y en diferido (vídeo bajo demanda) al mismo tiempo que funciona como archivo multimedia que hemos calificado de mediateca en línea (a la carta).

Las posibilidades de producción propia, emisión, recuperación y difusión son ilimitadas: la programación de dicho canal está abierta a un abanico muy amplio de actividades docentes y de investigación como seminarios, mesas redondas, defensa de tesis doctorales, entrevistas, videoconferencias, formación virtual y sus aplicaciones en programas de doctorado (como por ejemplo el doctorado iberoamericano presencial y en línea en ByD), el máster de bibliotecas, el programa oficial de posgrado (POP) de periodismo (en el que participa nuestro departamento con varias asignaturas), el establecimiento de un convenio de colaboración con la Universidad Iberoamericana Virtual juntamente con la Universidad de Extremadura, etc. (figura 10).

La plataforma está soportada por un gestor de contenidos mul-

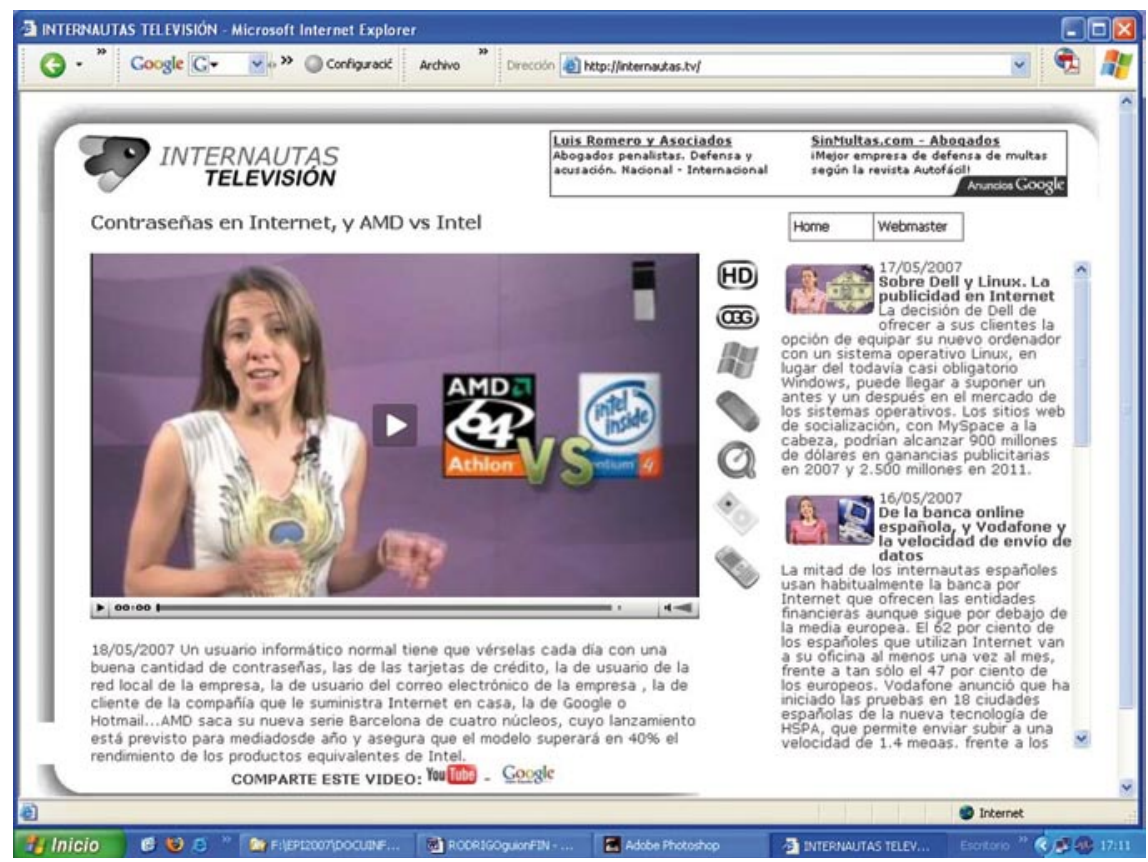

Figura 9. Internautas TV

http://internautas.tv/

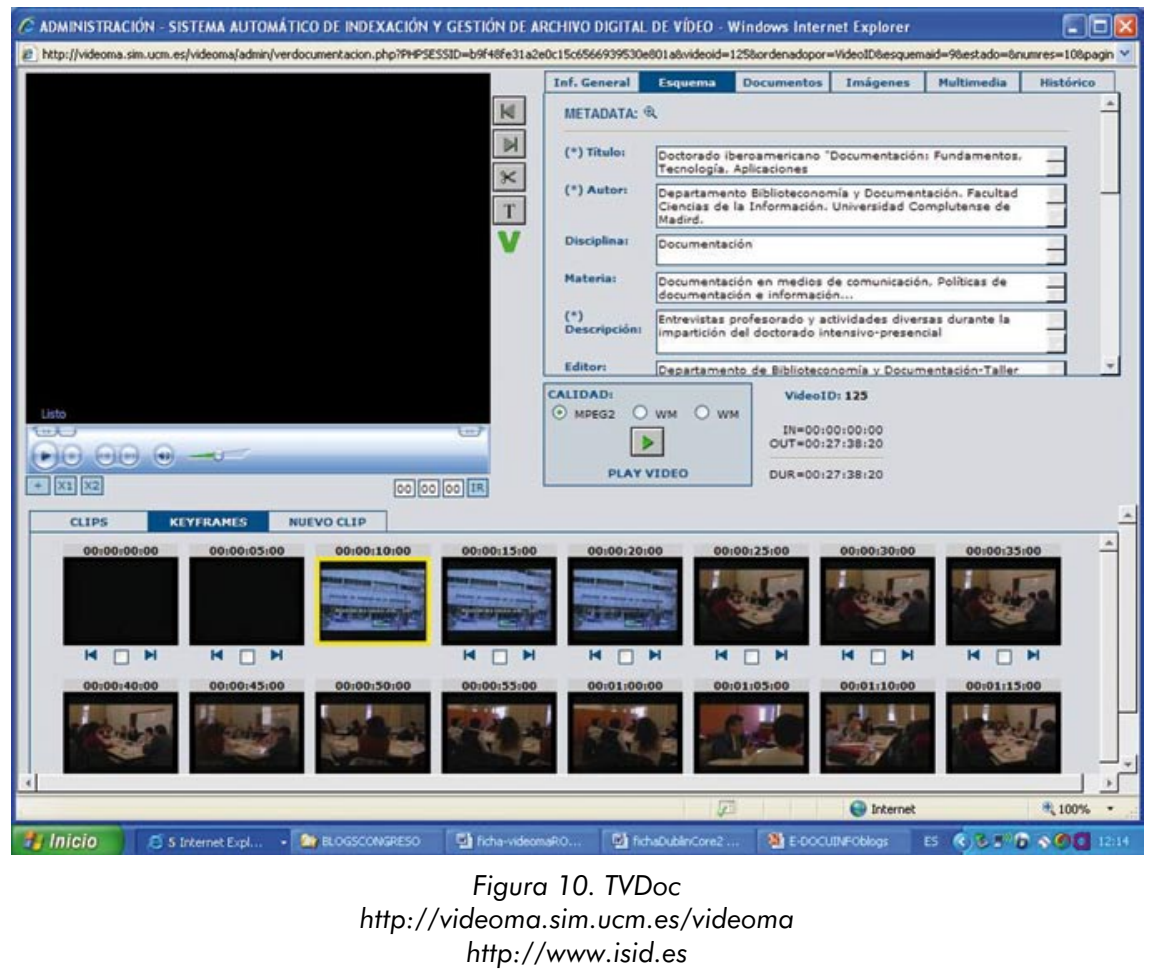

timedia o sistema automático de indexación y gestión de archivo digital, denominado Videoma ${ }^{9}$, al que se ha incorporado una plantilla-ficha para la descripción de los contenidos basada en metadatos, que en abril de 2007 se presentó en el II Congreso internacional de blogs y periodismo en $\mathrm{red}^{10}$, celebrado en la Facultad de Cien- cias de la Información de Madrid. Sus prestaciones son muy amplias, pudiéndose generar contenidos multimedia anejos asociados a los documentos descritos y formatos diversos de vídeo digital (mpeg2, wmv, avi) y de otros documentos (html, pdf, 16mm, dvd) y de imágenes fijas (jpg, gif, tiff, bmp, png) independientemente de las posibili- 
dades de edición y postproducción en línea (mediante la visualización de keyframes y generación de clips) y sus correspondientes aplicaciones docentes e investigadoras, tanto en el aula como fuera de ella, tareas todas ellas que se irán desarrollando a medio plazo (figuras 11, 12).

\section{"TVDoc está soportado por Videoma, que incorpora una plantilla para la descripción de contenidos (Dublin Core) aplicable a documentación audiovisual y multimedia"}

La descripción de los documentos se canaliza a través del estándar Dublin Core ${ }^{11}$, así como de una extensión de dicho formato a la documentación audiovisual, ViDe, un proyecto en proceso de estandarización definitiva que intenta realizar un perfil de aplicación para el vídeo digital, el cual comprende metadatos de tipo administrativo y estructural. Este modelo se basa en la norma general propuesta por Dublin Core con la intención de ofrecer un esquema con el que describir la creación, difusión, acceso y almacenamiento de documentos audiovisuales en formato digital. Dentro de un espectro más relacionado con las bibliotecas se dispone del Data dictionary for audio/video metadata, un diccionario elaborado en la Biblioteca del Congreso de los EUA, dentro de un proyecto de preservación de documentos audiovisuales en formato digital. Su principal objetivo es diseñar un sistema de referencia sobre el contenido de los documentos audiovisuales. Comprende campos que facilitan el almacenamiento y la gestión de las colecciones de este tipo de materiales. Por nuestra parte hemos realizado una adaptación de las propuestas de ViDe para el ámbito educativo e

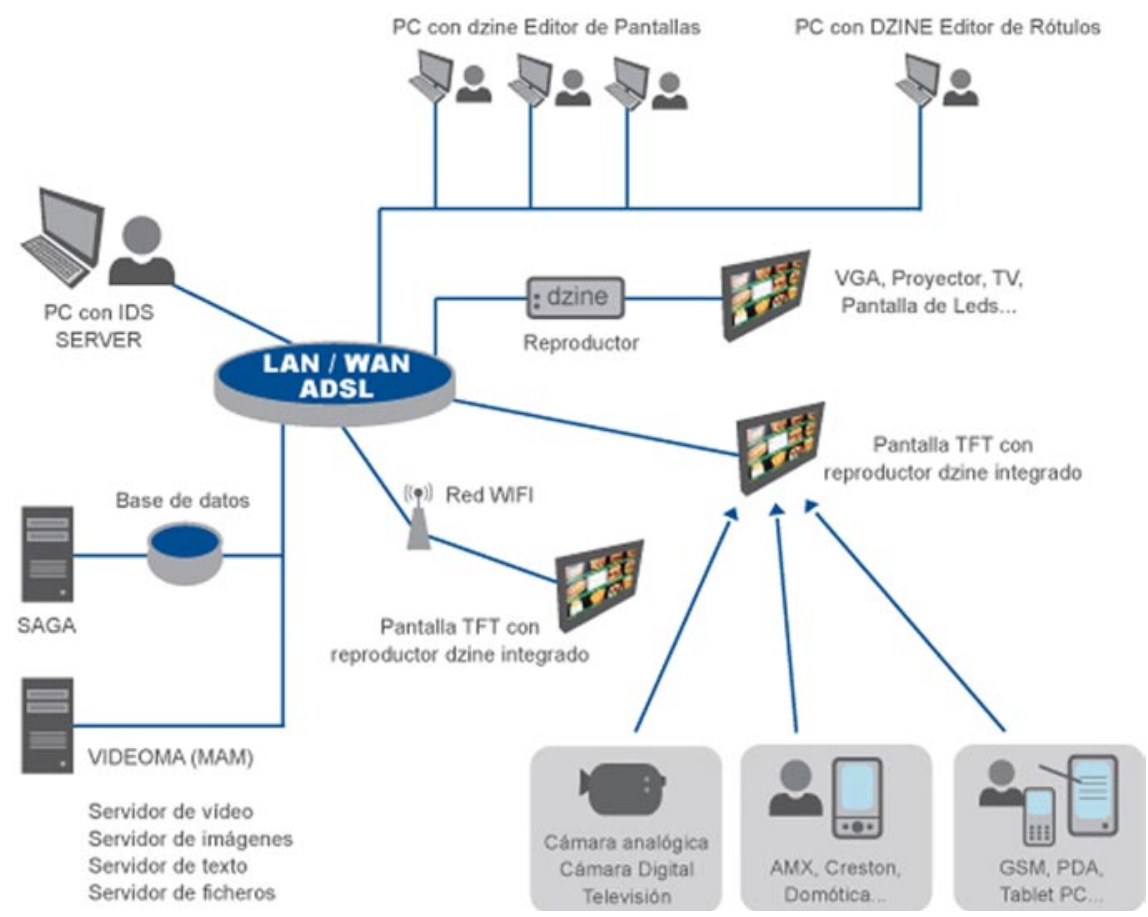

Figura 11. Videoma: configuración LAN, WAN, ADSL

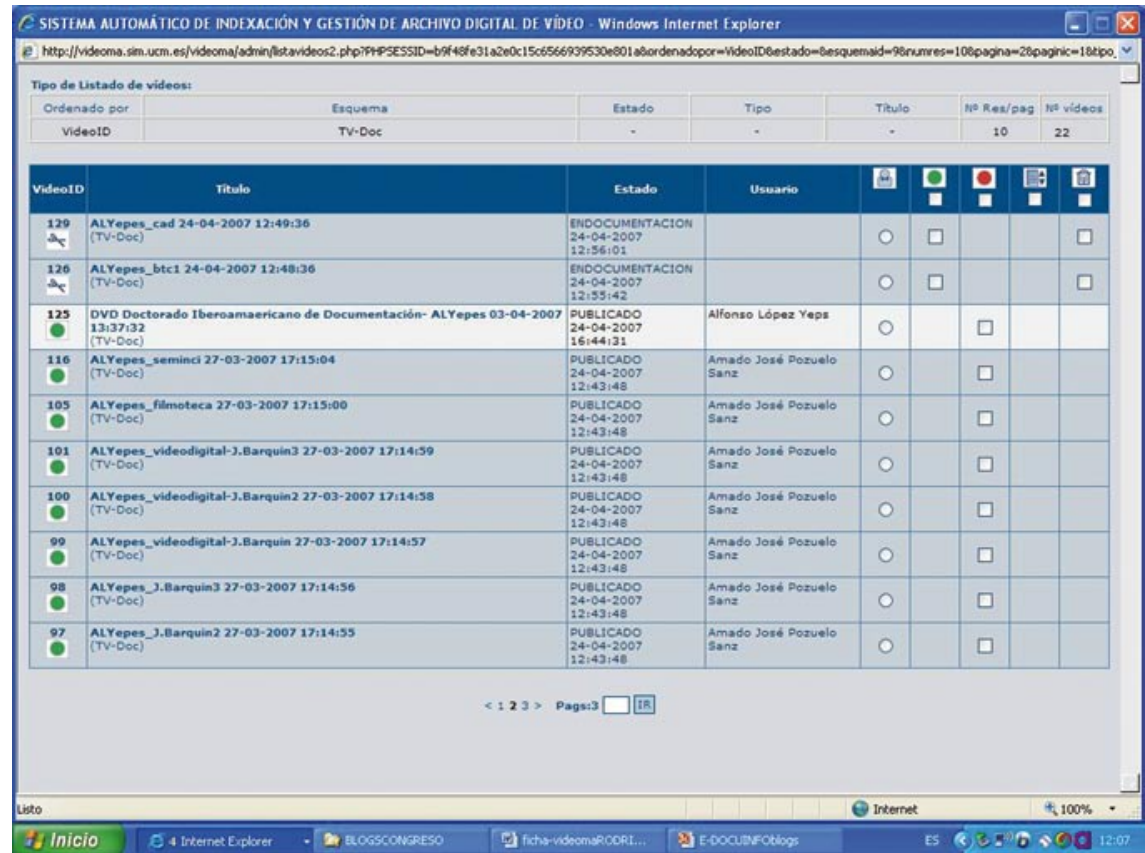

Figura 12. Videoma: ejemplos vídeo bajo demanda

investigador en la que se incluyen aspectos como el tratamiento de los derechos de autor que no se habían perfilado con precisión en la propuesta original (figuras 13, 14).

Los contenidos disponibles en $T V D o c$, en el momento de elaboración de este trabajo, se concretan a 270 vídeos y 215 imágenes, cantidad abierta permanentemente a su ampliación puesto que se siguen celebrando actividades de interés e incorporándose documentos. En tanto que el objetivo (además de la programación en tiempo real y en diferido) es establecer una mediateca en línea bajo demanda, se piensa ampliar a corto plazo la estructura de contenidos con la posibilidad de acceso a documentos sonoros y multimedia. El acceso a los mismos se realiza en la actualidad a través de 
una url concreta, debiendo teclearse "tvdocnet" (usuario y contraseña), para acceder a continuación a "Búsquedas", y desde ahí a "Esquema TV-Doc", para realizar la consulta sobre toda la información archivada ("General") o bien especificando si se quieren recuperar "Vídeos", "Imágenes", etc. La recuperación (que en todo momento se puede personalizar) se efectúa sobre la ya mencionada ficha de metadatos, so- bre un campo concreto o de forma generalizada, obteniéndose todo tipo de documentos asociados a dicha consulta (vídeo, imagen, etc.), con información relacionada: duración, formatos, dimensiones y otros datos de interés para el usuario.

http://videoma.sim.ucm.es/videoma

A muy corto plazo, a partir de septiembre-octubre de 2007 (preci-

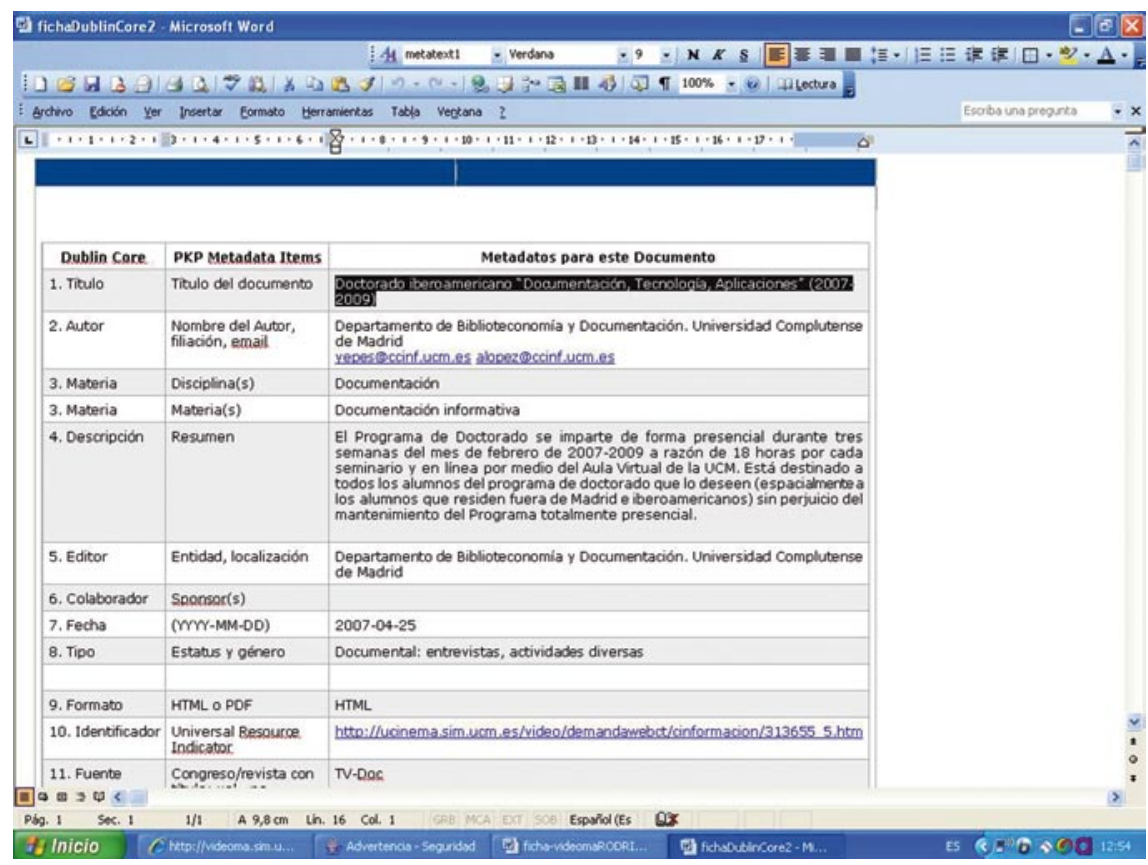

Figura 13. Videoma: metadatos Dublin Core

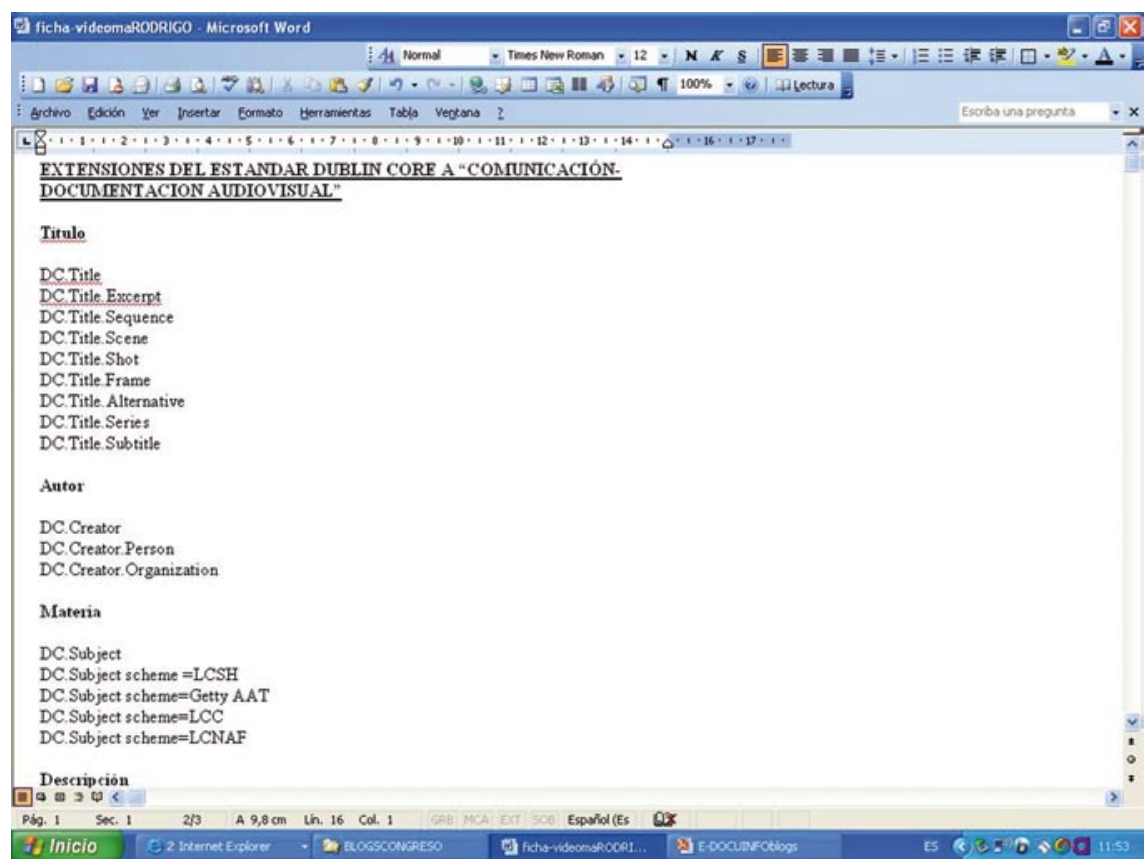

Figura 14. Videoma: metadatos extensión documentación audiovisual

\section{"TVDoc es un canal temático de documentación por televisión vía internet, una plataforma iptv"}

samente coincidiendo con la publicación de este trabajo) el acceso a los contenidos se automatizará considerablemente, evitando tener que teclearse claves y reduciéndose los pasos para acceder a la información (figura 15). Los bloques temáticos aparecen sistematizados en TVDoc de forma idéntica a los establecidos en $e$-DocuInfo, quedando claramente reflejados (según corresponda al documento) en el campo "Fuente": investigación, servicios y centros de documentación, tecnología digital, formación, publicación y bases de datos, propiedad intelectual y derechos de autor; con su aplicación correspondiente, claro está, a documentación periodística, sonora, cinematográfica, televisiva, publicitaria y de relaciones públicas.

\section{Conservación, preservación y difusión del patrimonio científico de la empresa informativa: fondos en red e interconexión de instituciones}

La propuesta de trabajo en la línea expresada en los epígrafes anteriores, y que conecta con la filosofía e-DocuInfo y TV-Doc, supone una contribución a la conservación, preservación y difusión del patrimonio documental cinematográfico. En este sentido hemos estado trabajando en el período abril 2006-mayo 2007 en un proyecto subvencionado a través de la OTRI (Oficina de Transferencia de Resultados de Investigación) por la Consejería de Cultura-Filmoteca de Andalucía con la colaboración del Servicio de Documentación Multimedia. Ha 
consistido en la creación de un sitio en internet con los fondos fílmicos del cineasta José Val del Omar, de cuya obra posee los derechos de propiedad la Filmoteca de Andalucía. Accesible desde e-DocuInfo ${ }^{12}$ (figura 16), próximamente estará también integrado en la web de la Filmoteca de Andalucía en la sección de nueva creación "Cineastas andaluces", abierta a su actualización permanente.

Dicho fondo documental ha quedado estructurado en las siguientes áreas de trabajo: "Creación y obra", "Contexto histórico", "Innovación", "Herramientas para el estudio", "Archivo en línea" y "Más información". Hasta el momento se ha completado exhaustivamente "Contexto histórico" y "Archivo en línea" (sistematizado en numerosas temáticas, con un inventario de materiales que reúne 624 artículos y unas 2.500 imágenes correspondientes a documentos escaneados, clasificados pertinentemente). Y a través de "Más información" se accede a numerosos y variados contenidos multimedia sobre la biografía, historia, estudios, pensamiento, creación y obra e innovación (invención técnica) herramientas (equipos y prototipos) del cineasta.

http://multidoc.rediris.es/valdelomar

Previamente a esta actuación y también sobre información cinematográfica en línea, en 2002 se plasmó en el marco del Programa del Amo, un proyecto sobre "Fuentes del cine español" dirigido a estudiantes norteamericanos en estrecha relación con sus investigaciones sobre cine y literatura. Planteado y elaborado también en el ámbito de Multidoc, se estableció con este fin un convenio de colaboración con la University of California-Davis a través del Vicerrectorado de Relaciones Internacionales de la UCM.

http://www.ucm.es/info/multidoc/amoproyecto/default.html

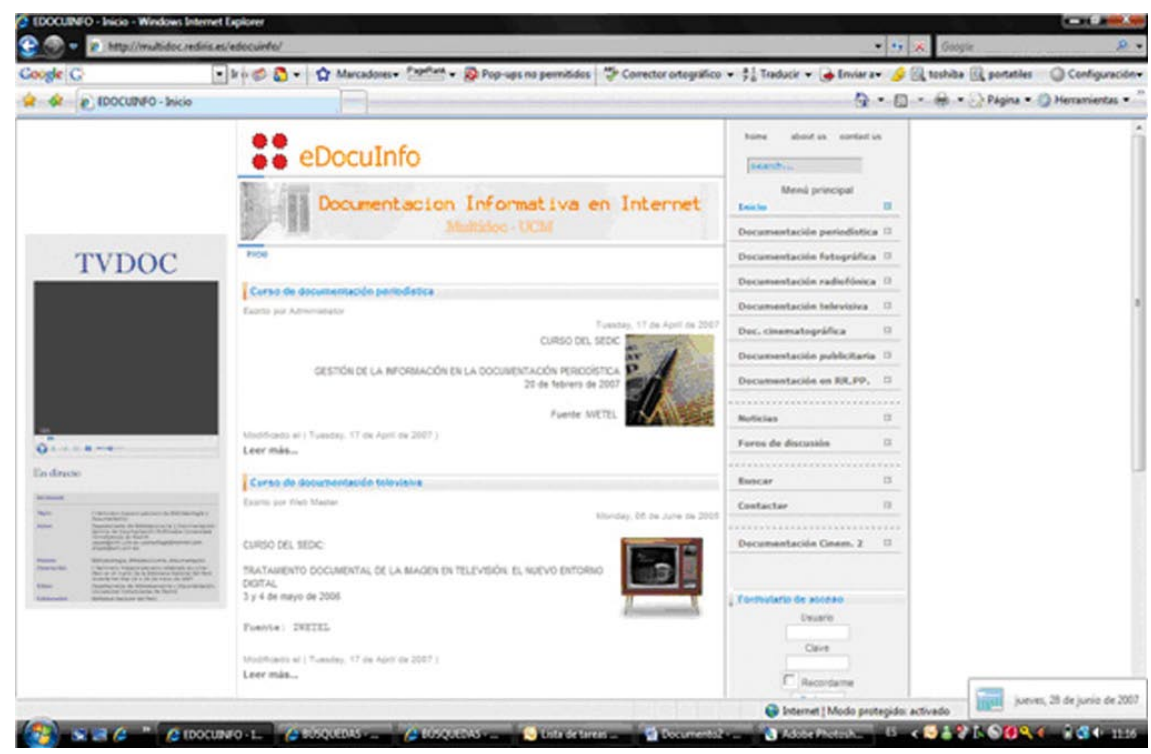

Figura 15

Nuestro deseo es participar y contribuir en lo posible, con iniciativas de esta índole, en ese magno proyecto de investigación de la $B i$ blioteca Digital Europea emprendida por la Unesco y en el de la Biblioteca Digital Universal. Desde nuestro punto de vista debería especificarse en este concepto tan amplio de biblioteca el desarrollo y reconocimiento de términos como filmoteca, cinemateca, fonoteca, fototeca, videoteca, mediateca, etc., digital europea y digital universal, de modo que los fondos documentales estén accesibles, o de alguna forma consultables vía web, gratuitamente o mediante pago en función de la propiedad intelectual de los documentos. Podría asimismo paliarse de algún modo o en parte los horarios restringidos de las instituciones pensando, claro está, en el trabajo que llevan a cabo investigadores, profesores, estudiantes, comunicadores en general y otros usuarios reales y potenciales, lo que supondría un acceso permanente a la información en línea.

Conviene mencionar en este punto el proyecto Europeana, contribución francesa a la Biblioteca Digital Europea, que contará en 2010 con más de seis millones de libros, películas, fotografías y otros documentos de países de la Unión
Europea accesibles a través de un único portal en internet. Además de promover la digitalización del patrimonio cultural europeo, el proyecto pretende ser una respuesta al de Google, que prevé publicar en la Red 15 millones de obras de bibliotecas. En este sentido, en septiembre de 2006 se establecía un acuerdo de colaboración entre Google y la Complutense de Madrid para digitalizar cientos de miles de libros que no están sujetos a derechos de autor, propiciando así que su contenido íntegro esté accesible ${ }^{13}$.

Abundando en lo expresado, en abril de 2007 el Grupo de expertos de alto nivel sobre bibliotecas digitales de la Comisión Europea publicó el "Informe sobre preservación digital, obras huérfanas y ediciones agotadas, aspectos concretos relacionados con su aplicación" ${ }^{14}$. Su objetivo es asesorar a la $C E$ sobre cuestiones de derechos de autor relativas a la digitalización, la accesibilidad en línea y la preservación digital de los materiales culturales. Entre otras cosas, recomienda los acuerdos voluntarios entre las bibliotecas y los titulares de derechos para facilitar la digitalización y preservación de las obras huérfanas $\mathrm{y}$ ediciones agotadas. El informe también urge a que se celebre un debate sobre cómo garantizar un ac- 


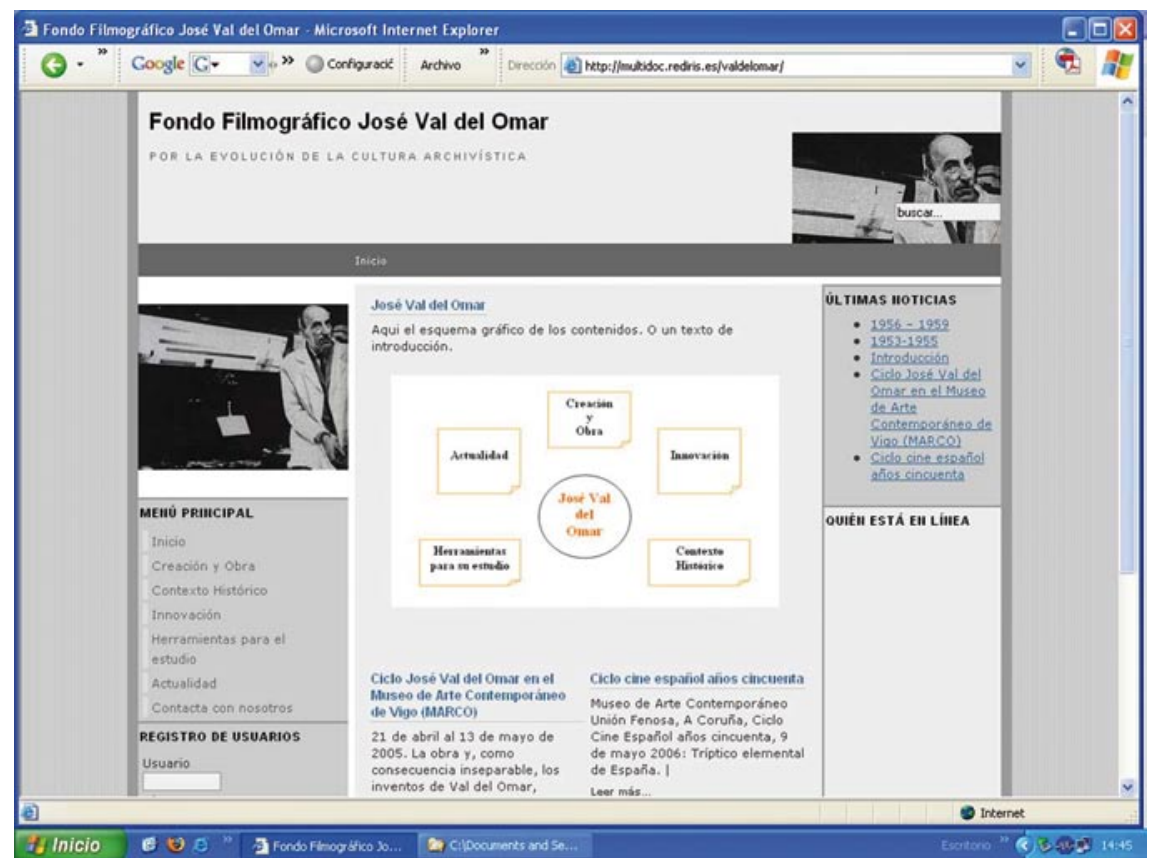

Figura 16. Fondo filmográfico Val del Omar

http://multidoc.rediris.es/valdelomar

ceso más abierto a la investigación científica y cómo mejorar la cooperación entre los sectores público y privado. El grupo de expertos fue creado hace un año por la $D G S o$ ciedad de la Información y forma parte de los esfuerzos de la $C E$ por poner en línea el rico patrimonio cultural y científico de Europa (podría añadirse que de Iberoamérica, desarrollando las actuaciones y propuestas de trabajo pertinentes).

A largo plazo tenemos prevista la actualización de la Enciclopedia del cine español: 100 años de cine español (1895-1996) ${ }^{15}$, con información multimedia correspondiente a la última década transcurrida, que podría llevar por título Cine español y patrimonio cinematográfico en red (1997-2007). Dicha investigación mantendría viva la línea de contribución aludida, como actuación generada nuevamente desde el ámbito universitario y como propuesta de implicación colaborativa con la empresa especializada pública y privada para la distribución del conocimiento cinematográfico.

\section{Referencias}

1. López-Yepes, Alfonso; Pérez-Agüera, JoséRamón. "Líneas de investigación y desarrollo tecnológico en el Departamento de Biblioteconomía y Documentación de la Universidad Complutense". En: Documentación de las ciencias de la información, 2005, v. 28, 2005.

http://www.ucm.es/BUCM/revistas/inf/02104210/ articulos/DCIN0505110033A.PDF

López-Yepes, Alfonso (dir.); Cuadra-Colmenares, Elena; Sánchez-Jiménez, Rodrigo; PérezAgüera, José-Ramón. El cine en la era digital: aplicaciones de la documentación cinematográfica (1992-2005). Madrid, Fragua, 2006. Contiene numerosos materiales didácticos multimedia procedentes del Servicio de Documentación Multimedia.

López-Yepes, Alfonso. "Formación semipresencial y virtual en documentación informativa en el ámbito del Departamento de Biblioteconomía y Documentación de la Universidad Complutense (1998-2007)". En: Anales de documentación. Revista de biblioteconomía y documentación, 2007, v. 10.

http://www.um.es/fccd/anales/ad10/ad1014.pdf

2. "Campus virtual UCM, un espacio en internet de apoyo a tus estudios. Asignaturas en la web". En: Tribuna complutense, 2007, junio, p. 5.

3. López-Yepes, Alfonso; Pérez-Agüera, JoséRamón. "CineDocNet, TVDocNet: una comunidad virtual de usuarios de documentación audiovisual (cinematográfica y televisiva)". En: $E l$ profesional de la información, 2002, septiembreoctubre, v. 11, n. 5.

http://www.elprofesionaldelainformacion.com/ contenidos/2002/septiembre/2.pdf

López-Yepes, Alfonso (dir.). Documentación cinematográfica: Mediateca. Proyecto de Innovación Educativa, financiado por el Vicerrectorado de Estudios de la Universidad Complutense. Madrid, Editorial Complutense, 2003 (cd-rom multimedia y accesible vía web)

http://multidoc.rediris.es/mediateca/

"Documentación audiovisual en línea". En: Rovira, Cristòfol; Codina, Lluís (dir.). Documen- tación digital. Barcelona: Grupo de investigación DigiDoc. Instituto Universitario de Lingüística Aplicada. Departamento de Periodismo y de Comunicación Audiovisual. Universidad Pompeu Fabra, 2006

http://www.documentaciondigital.org

"Cine, filmotecas y archivos fílmicos españoles: repertorio básico de recursos web. Una propuesta para el ámbito mexicano”. En: III Seminario hispano-mexicano de investigación en bibliotecología y documentación-CUIB/UNAM, 2006.

"Documentación cinematográfica: el cine en la era digital". En: Rovira, Cristòfol; Codina, Lluís (dir.). Documentación digital. Barcelona: Grupo de Investigación DigiDoc. Instituto Universitario de Lingüística Aplicada. Departamento de Periodismo y de Comunicación Audiovisual. Universidad Pompeu Fabra, 2007.

http://www.documentaciondigital.org

Portal de documentación cinematográfica: CineDocNet.

http://multidoc.rediris.es/seguridad/descarga/cinedocnet

http://multidoc.rediris.es/cinedocnet 3

Portal de documentación publicitaria: PubliDocNet

http://multidoc.rediris.es/publidocnet3/

Portal de documentación en relaciones públicas. http://multidoc.rediris.es/docrrpp

Portal de publicaciones electrónicas de biblioteconomía y documentación: $E-B y D o c$ http://multidoc.rediris.es/e-bydoc/

4. ITU Internet Reports 2006: digital.life, 2006, 8th edition.

http://www.itu.int/dms_pub/itu-s/opb/pol/S POL-IR.DL-2-2006-R1-SUM-PDF-E.pdf

Evaluación de la Sociedad de la Información-Indicadores de las Telecomunicaciones Mundiales/ TIC y del Indice de Oportunidad TIC-2007.

http://www.itu.int/pub/D-IND-ICTOI-2006/es/

"El aumento del ancho de banda" (editorial). En Producción profesional, 2007, abril.

5. Borjas, Sydney. "Convergencia de contenidos y tecnología. Impacto de las tecnologías de conectividad (banda ancha)". En: Cinevideo20, 2007 , mayo, p. 30

6. Pablos, Emiliano de. "Convergencia tecnológica a propósito de la banda ancha”. En: Cinevideo20, 2007, mayo, p. 19.

7. "El curso natural de la televisión: verla en internet". En: Teleinforme, 2007, abril, p. 49.

8. Turró, Carlos; Pasamar, José-Manuel; Jiménez, Miguel; Busquets, Jaime. "Usando intensivamente la red: 152 Mbps de multicast para distribuir TDT, satélite y canales educativos internos en la UPV". En: Boletín de RedIris, n. 78-79. http://www.rediris.es/rediris/boletin/78-79/ponencial4.pdf

YouTube.

http://www.youtube.com/

Google Video España. http://video.google.es/

Madridmas-Fundación para el conocimiento Madri+d.

http://www.madrimasd.org/cienciaysociedad/ mediatecal 
Internautas $T V$.

http://internautas.tv/

9. Videoma

http://www.isid.es

10. II Congreso internacional de blogs y periodis mo en red. Madrid, UCM, 26 de abril de 2007. http://www.ucm.es/info/congresoblog/

11. López-Yepes, Alfonso; Sánchez-Jiménez, Rodrigo; Pérez-Agüera，José-Ramón. "Tratamiento de la documentación audiovisual en el entorno digital: iniciativas de metadatos y lenguajes de descripción multimedia". En: $E$ profesional de la información, 2003, noviembrediciembre, n. 6.

http://www.elprofesionaldelainformacion.com/ contenidos/2003/noviembre/3.pdf

"Agentes de información en entornos distribuidos y sistema multiagente de recuperación de información". En: Investigación bibliotecológica, 2005, julio-diciembre, v. 19, n. 39

Sobre metadatos véase también: Méndez, Eva "Dublin Core, metadatos y vocabularios". En El profesional de la información, 2006, marzoabril, v. 15, n. 2, pp. 84-86.

http://elprofesionaldelainformacion.metapress. com/app/home/contribution.asp? referrer $=$ paren t\&backto=issue, 1,9;journal,8,53; homemainpub lications, 1,1
Méndez, Eva; Bravo, Alejandro; López, Leandro-Mariano. "Microformatos: web 2.0 para el Dublin Core". En: El profesional de la información, 2007, marzo-abril, v. 16, n.2, pp. 107-113. http://elprofesionaldelainformacion.metapress. com/app/home/contribution.asp? referrer=paren t\&backto=issue,3,15; journal,2,53; homemainpu blications, 1,1

12. Fondo filmográfico José Val del Omar. http://multidoc.rediris.es/valdelomar

Filmoteca de Andalucía.

http://www.filmotecadeandalucia.com

13. «La Universidad Complutense 'vuelca' su biblioteca en Google. El centro académico madrileño llega a un acuerdo con el buscador estadounidense para digitalizar todos sus libros». Elpais.es/EFE-Madrid-26-09-06.

http://www.elpais.com/articulo/internet/Universidad/Complutense/vuelca/biblioteca/Google/ elpportec/20060926elpepunet_4/Tes

14. Report on digital preservation, orphan works and out-of-print works, selected implementation issues.

http://ec.europa.eu/information_society/newsroom/cf/document.cfm? action $=$ display \& doc $i d=295$

Annex: model agreement for a licence on digitisation of out of print works. http://ec.europa.eu/information_society/newsroom/cf/document.cfm? action=display\&doc $i d=296$

15. López-Yepes, Alfonso (dir.). Enciclopedia del cine español: 100 años de cine español (1896-1996). Madrid: Micronet, 1996 (cd-rom).

"Enciclopedia del cine español, una publicación interactiva en soporte óptico". Cd-Rom. En: Cuadernos de documentación multimedia, 1996, n. 8. http://www.ucm.es/info/multidoc/multidoc/revista/cuadern $5 /$ cdcine.htm

Todas las referencias electrónicas relacionadas, así como las que aparecen referenciadas en el interior del texto, han sido consultadas con fecha: 03-07-2007.

\section{Alfonso López-Yepes, Rodrigo}

Sánchez-Jiménez, Servicio de Documentación Multimedia (Multidoc), Departamento de Biblioteconomía y Documentación, Facultad de Ciencias de la Información, Universidad Complutense de Madrid. alopez@ccinf.ucm.es rsanchezj@ccinf.ucm.es

\section{nature.com}

\section{es ciencia}

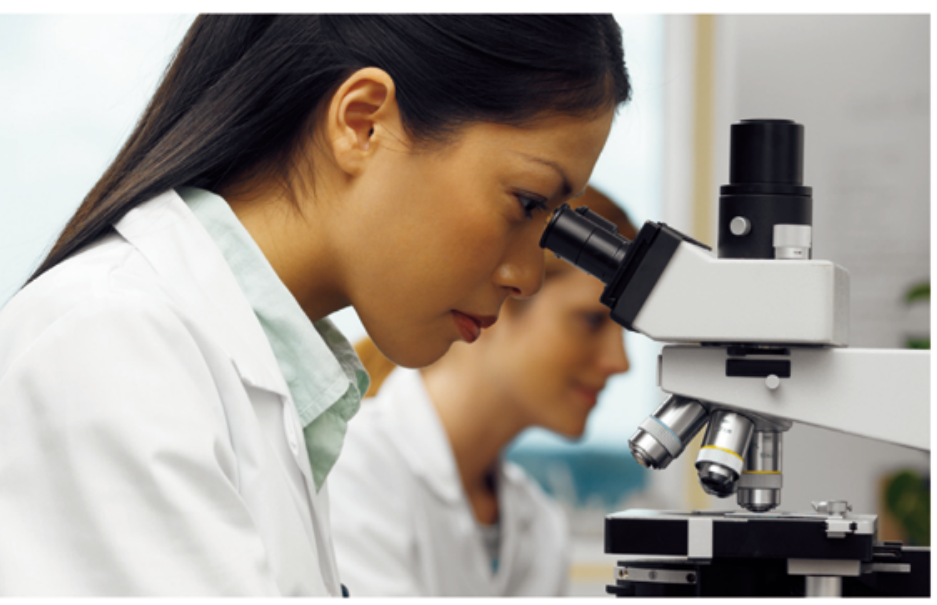

nature.com

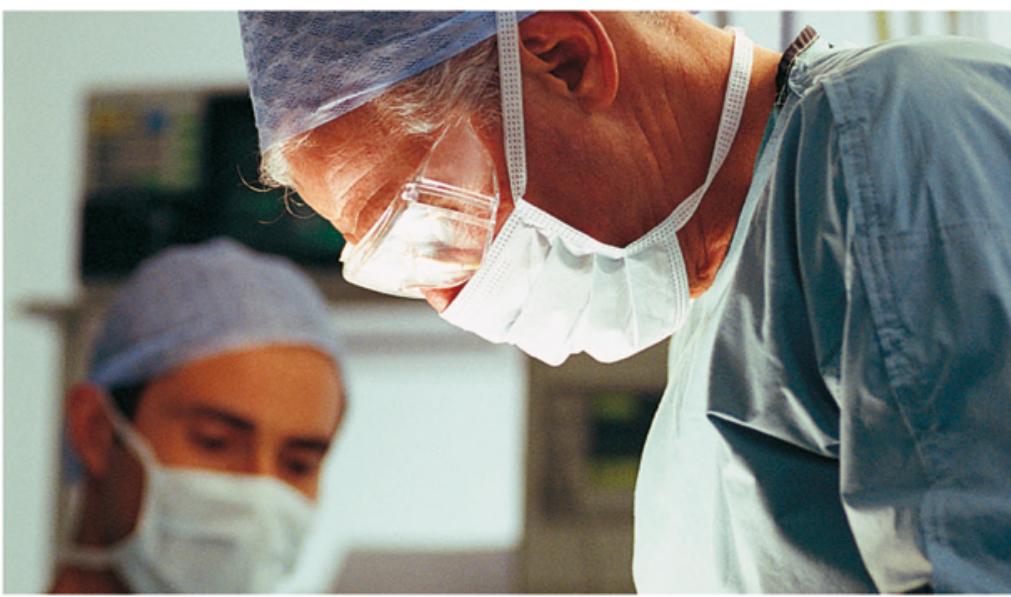

\section{Está en nature.com}

\section{Consiga su acceso a nature.com con una Licencia de acceso NPG y elija entre las revistas más valoradas en ciencia y medicina. Su licencia de acceso le garantiza informes de uso, herramientas de promoción, derechos de post-anulación y servicio de atención al cliente.}

